05

\title{
Анализ проникающей способности стержневых ударников из пористых материалов
}

\author{
(C) В.Ф. Толкачев ${ }^{1}$, С.А. Зелепугин ${ }^{1,2}$ \\ ${ }^{1}$ Национальный исследовательский Томский государственный университет, \\ 634050 Томск, Россия \\ ${ }^{2}$ Томский научный центр СО РАН, \\ 634055 Томск, Россия \\ e-mail: szel@yandex.ru
}

Поступило в Редакцию 25 декабря 2018 г.

В окончательной редакции 19 апреля 2019 г.

Принято к публикации 13 мая 2019 г.

\begin{abstract}
Представлены результаты экспериментального исследования и математического моделирования проникания стержневых ударников из пористых материалов в металлические преграды при осесимметричном высокоскоростном ударе. Результаты исследования свидетельствуют о существенном влиянии пористости материала ударника на процесс проникания, которая при сверхвысоких скоростях соударения приводит к увеличению глубины проникания в сравнении с ударниками монолитной плотности при равенстве их массы и диаметра. Данный эффект связывается с ускоренным образованием локализованных полос сдвига и последующей фрагментацией материала. Одним из возможных подходов для оценки глубины проникания может служить предлагаемая приближенная (инженерная) методика, в которой учитываются динамические прочностные характеристики материалов взаимодействующих тел. Проведено сравнение результатов расчетов по предложенной методике с экспериментальными данными, показавшее хорошее качественное и количественное их соответствие.
\end{abstract}

Ключевые слова: высокоскоростное проникание, пористый стержневой ударник, пробивное действие.

DOI: $10.21883 / J T F .2019 .12 .48485 .442-18$

Возможности модернизации образцов высокоэффективных ударников из традиционных высокопрочных сталей и высокоплотных сплавов при функционировании их в условиях высокоскоростного удара к настоящему времени исчерпаны. Перспективным направлением усиления проникающей способности ударников кинетического действия является применение композиционных материалов комбинированного строения на основе тугоплавких соединений [1-3], либо неклассических материалов, например, сильнопористого материала с низкой и средней удельной плотностью [4-8].

Природа пористых материалов многообразна, они могут иметь самую различную структуру - порошки, тела с внутренними пустотами, керамика, ячеистые и др. Пористость вещества определяется как $\alpha=\rho_{00} / \rho_{0}$, где $\rho_{00}$ - плотность пористого вещества, $\rho_{0}-$ плотность вещества в монолитном, беспористом состоянии. Процесс ударного сжатия пористых тел обладает определенными особенностями. Важность таких исследований впервые отмечена в [9]. Необходимо отметить, что цикл дальнейших исследований связан с интенсивным развитием авиационной, ракетной и космической техники. Исследования ударно-волновых свойств пористых материалов подтвердили их необходимость для решения ряда научно-технических задач, включающих высокоскоростные соударения и др. $[10,11]$. В частности, ведутся широкомасштабные поисковые исследования эффективных способов защиты Земли от опасных космических объектов (астероидов, метеороидов) различной массы, летящих со сверхвысокими скоростями. В этом направлении можно на околоземной орбите строить космические модули из сыпучих (порошкообразных) материалов в качестве ударников различной массы и удлинения, которые будут способны при высокоскоростном взаимодействии либо разрушать космические тела, либо отклонять их траекторию движения.

Процессы высокоскоростного соударения твердых тел активно исследуются экспериментально, численно и с применением приближенных математических подходов [12-15]. Экспериментально и с помощью численного моделирования было показано [4], что пористый ударник, изготовленный из металлических опилок, проникает в гидродинамическом режиме в стальную мишень глубже, чем монолитный ударник, при условии равенства масс и диаметров, причем с увеличением пористости его преимущество в проникающей способности над монолитным возрастает. Очевидно, что увеличение глубины проникания пористых ударников при идентичных условиях связано со значительным увеличением их длины по мере разуплотнения материала. Однако представленные в [4] результаты носят ограниченный характер, при этом не рассматриваются физические аспекты выявленного эффекта, что не позволяет построить обобщающую модель процесса, применимую в иных условиях взаимодействия.

Целью настоящей работы является расширение знаний о механизме проникания стержневых ударников из материалов заданной пористости и возможности про- 
гнозирования последствий процесса высокоскоростного взаимодействия на характер и параметры проникания и разрушения. Для достижения поставленной цели предложена приближенная (инженерная) методика прогнозирования глубины проникания пористых ударников в металлическую преграду. Методика базируется на гидродинамических представлениях с учетом прочностных характеристик взаимодействующих материалов [16-18] и степени сжимаемости материала ударника в контактной области с преградой.

При ударно-волновом взаимодействии поведение ударников из пористых материалов характеризуется рядом особенностей. На начальной стадии высокоскоростного взаимодействия работа сил внешнего давления затрачивается на закрытие пустот, на уплотнение вещества и приведение его к нормальному объему. Эта работа связана с преодолением сил трения между частицами, с раздроблением частиц, со смятием волокон и т.д. в зависимости от типа структуры. Для совершения этой работы требуются сравнительно небольшие давления, масштабом которых служат пределы прочности материалов. Для учета давлений сжатия в математическую модель вводится параметр $P_{f}$, полуэмпирическое соотношение для определения которого получено из анализа экспериментальных данных, результатов теоретических и численных исследований [3,9-11].

Алгоритм расчета глубины проникания стержневых ударников в преграду развит на основе имитационной модели высокоскоростного проникания стержневых ударников с учетом ударно-волновых и прочностных свойств материалов взаимодействующих тел. Процесс проникания ударника в преграду описывается системой кинематических уравнений [16-18], в которой дополнительно учитывается давление сжатия пористого вещества $P_{f}$ при переходе к сплошному состоянию:

$$
\begin{gathered}
P_{f}=\frac{c_{0}^{2}\left(\rho_{0}-\rho_{00}\right)^{2}}{\rho_{00}\left[s /(s-1)+\rho_{0} / \rho_{00}\right]^{2}}, \\
\frac{d V}{d t}=-\frac{\sigma^{d}}{\rho_{00} l(t)}, \\
\frac{d l}{d t}=-(V-U), \\
d L=U d t, \\
0.5 A \rho_{00}(V-U)^{2}+\sigma^{d}+P_{f}=0.5 \rho_{t} U^{2}+H_{D}, \\
A=\left(c_{00}+s U\right) /\left(c_{00}+(s-1) / U\right),
\end{gathered}
$$

где $\rho_{00}-$ плотность пористого материала ударника; $\rho_{0}$ и $\rho_{t}-$ плотности материала ударника и преграды соответственно; $V, l-$ текущая скорость ударника и его длина; $U-$ скорость контактной поверхности (массовая скорость); $L-$ глубина проникания; $\sigma^{d}-$ динамический предел текучести ударника; $H_{D}$ - динамический предел прочности материала преграды; $A-$ степень динамического сжатия, определяемая из ударной адиабаты материала ударника $D=c_{00}+s U$. Константам $c_{00}$ и $s$
Параметры пористых и монолитных материалов

\begin{tabular}{c|c|c|c|c|l}
\hline № & Материал & $\alpha=\rho_{00} / \rho_{0}$ & $\rho_{00}, \mathrm{~g} / \mathrm{cm}^{3}$ & $c_{00}, \mathrm{~km} / \mathrm{s}$ & $s$ \\
\hline 1 & $\mathrm{~W}$ & 1.00 & 19.17 & 4.02 & 1.235 \\
2 & $\mathrm{~W}$ (пористый) & 0.70 & 13.36 & 3.75 & 2.07 \\
3 & $\mathrm{~W}$ (пористый) & 0.46 & 8.87 & 0.25 & 1.72 \\
4 & $\mathrm{~W}$ (пористый) & 0.29 & 5.5 & 0.025 & 1.50 \\
5 & $\mathrm{~W}$ (пористый) & 0.24 & 4.6 & 0.025 & 1.50 \\
6 & $\mathrm{Cu}$ & 1.00 & 8.93 & 4.506 & 1.418 \\
7 & Сплав (Ni-Cu) & 1.00 & 8.89 & 4.08 & 1.547
\end{tabular}

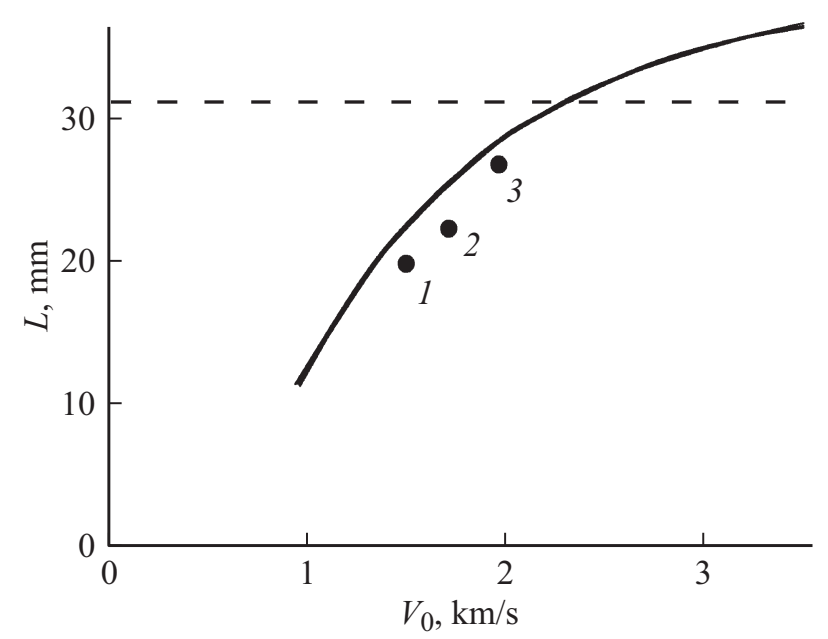

Рис. 1. Сравнение расчетных и экспериментальных данных по глубине проникания стержней из пористого вольфрама в стальную преграду: линия - расчет: $\rho_{00}=13.36 \mathrm{~g} / \mathrm{cm}^{3}$, $l_{0}=24 \mathrm{~mm}$; точки - эксперимент: $1-V_{0}=1470 \mathrm{~m} / \mathrm{s}, \rho_{00}=$ $=13.0 \mathrm{~g} / \mathrm{cm}^{3}, l_{0}=24 \mathrm{~mm} ; 2-V_{0}=1750 \mathrm{~m} / \mathrm{s}, \rho_{00}=12.5 \mathrm{~g} / \mathrm{cm}^{3}$, $l_{0}=24.3 \mathrm{~mm} ; 3-V_{0}=2100 \mathrm{~m} / \mathrm{s}, \rho_{00}=13.2 \mathrm{~g} / \mathrm{cm}^{3}, l_{0}=24.1 \mathrm{~mm}$.

соответствуют значения, приведенные в [19]. $\sigma^{d}=\alpha \sigma_{0}$, $\sigma_{0}$ - динамический предел текучести сплошного материала ударника.

По данной методике выполнены расчеты глубины проникания в стальные преграды ударников из пористого вольфрама, физико-механические характеристики и ударные адиабаты которого представлены в таблице, аппроксимированные в соответствии с данными [19].

Корректирующие константы модели подбирались при сравнении результатов расчетов с данными специально выполненных экспериментов. На рис. 1 представлено сравнение расчетной зависимости проникания ударника из пористого вольфрама $\left(\rho_{00}=13.36\right)$ с экспериментальными данными. Наблюдается хорошее качественное и количественное согласование результатов расчета с данными экспериментов.

На рис. 2 представлены расчетные зависимости глубины проникания $L$ равных по массе и диаметру ударников из материалов различной пористости с матрицей из вольфрама. В качестве базового ударника выступал вольфрамовый ударник с параметрами: длина $l_{0}=60 \mathrm{~mm}$, диаметр $d_{0}=6 \mathrm{~mm}$, динамический предел текучести $\sigma_{0}=1.2 \mathrm{GPa}$. Преграда - высокопрочная сталь с преде- 


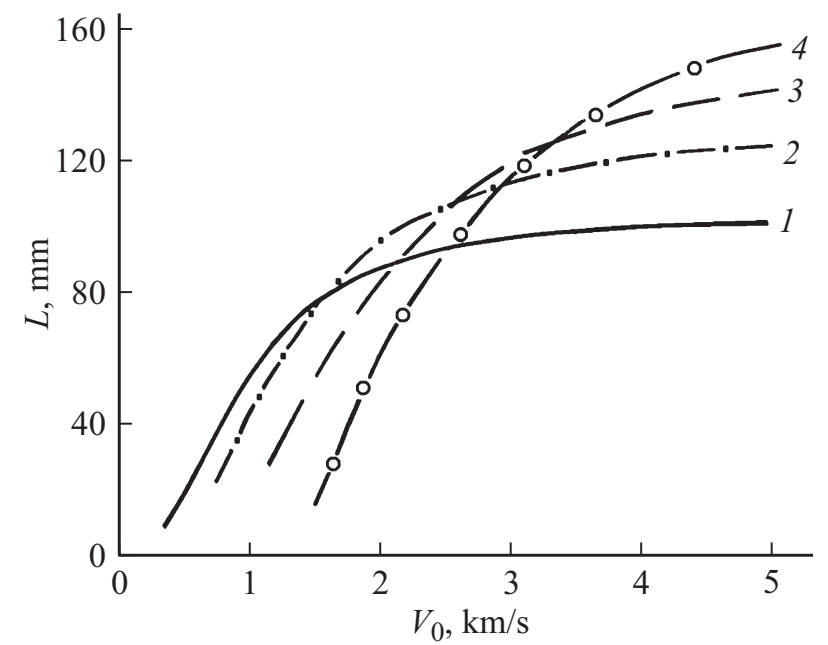

Pис. 2. Зависимости глубины проникания ударников от скорости удара при различной пористости материала: $m_{0}=$ constant; $d_{0}=$ constant; $1-\rho_{0}=19.17 \mathrm{~g} / \mathrm{cm}^{3}, 2-\rho_{00}=13.36 \mathrm{~g} / \mathrm{cm}^{3}$, $3-\rho_{00}=8.87 \mathrm{~g} / \mathrm{cm}^{3}, 4-\rho_{00}=5.55 \mathrm{~g} / \mathrm{cm}^{3}$.

лом текучести $400 \mathrm{GPa}$ и динамическим пределом прочности $H_{D}=3.5 \mathrm{GPa}$. График иллюстрирует смещение предельных скоростей начала проникания ударников в сторону увеличения скорости удара, а также свидетельствует о том, что с увеличением скорости соударения ударники из материалов с большей пористостью проникают в преграду глубже. Так, при скорости соударения $4 \mathrm{~km} / \mathrm{s}$ пористый ударник с плотностью материала $\rho_{00}=8.87 \mathrm{~g} / \mathrm{cm}^{3}$ (кривая 3, рис. 2) проникает в стальную мишень глубже на $30 \%$ в сравнении с вольфрамовым ударником с плотностью $\rho_{0}=19.17 \mathrm{~g} / \mathrm{cm}^{3}$ (кривая 1 ). Наблюдаемое увеличение проникающей способности ударников из пористых материалов в сравнении с монолитными ударниками, очевидно, при данной постановке задачи является результатом их значительной длины.

Также результаты свидетельствуют о том, что увеличение проникающей способности ударников из пористых материалов в сравнении с монолитными ударниками проявляется только при высоких скоростях удара. Так, пористый вольфрамовый ударник с плотностью материала $\rho_{00}=8.87 \mathrm{~g} / \mathrm{cm}^{3}$ начинает демонстрировать более глубокое проникание по сравнению с монолитным только для скоростей удара выше $2500 \mathrm{~m} / \mathrm{s}$. Более того, увеличение начальной длины монолитного стержня, очевидно, отодвигает точку данного перехода в область еще более высоких скоростей удара.

Для выявления влияния пористости материала ударника на глубину проникания были проведены оценки внедрения монолитных и пористых ударников из разных материалов с одинаковым значением плотности и геометрических размеров. На рис. 3 представлены графические зависимости относительной глубины проникания ударников из сплава $\mathrm{Ni}-\mathrm{Cu}$ (кривая $1-$ $\left.\rho_{0}=8.89 \mathrm{~g} / \mathrm{cm}^{3}\right)$, меди (кривая $2-\rho_{0}=8.93 \mathrm{~g} / \mathrm{cm}^{3}$ ) и пористого вольфрама (кривая $3-\rho_{00}=8.87 \mathrm{~g} / \mathrm{cm}^{3}$, $\alpha=0.47)$. Данные зависимости свидетельствуют о том, что ударники из пористого вольфрама при скоростях взаимодействия свыше $2000 \mathrm{~m} / \mathrm{s}$ проникают в стальную преграду глубже и эффект усиливается с увеличением скорости соударения.

Анализ приведенных результатов исследования и литературных данных позволяет предположить, что увеличение проникающей способности пористых ударников свидетельствует об изменении механизма проникания. Многочисленными баллистическими испытаниями с последующими металлографическими исследованиями было показано, что эффективность проникания длинных стержней при высоких скоростях взаимодействия зависит не только от прочности и пластичности материала, но и от того, как он пластически деформируется и разрушается (растекается) под действием сдвиговых деформаций, от того, как ударник в контактной области приобретает „грибовидную“ форму. Так, в традиционных вольфрамовых сплавах наблюдается позднее образование полос локализации сдвига с последующим отделением фрагментов материала ударника, что и определяет величину диаметра кратера $[2,20]$.

В пористом ударнике в процессе проникания вблизи поверхности контакта с преградой формируется присоединенная ударная волна $[10,11,17,18]$. Ее формирование обусловлено низкой скоростью звука в пористом материале. В этом случае можно предположить, что плотность материала скачкообразно возрастает на фронте ударной волны и при дальнейшем внедрении ударника на границе контакта она слабо меняется за счет постоянного втекания материала ударника с начальной скоростью взаимодействия. Можно также предположить, что в случае проникания пористых ударников наблюдается раннее образование полос локализации сдвига и отделение фрагментов. Такой механизм проникания позволяет ударнику быстро „сбрасывать“ деформированный материал, уменьшать площадь контакта и в результате

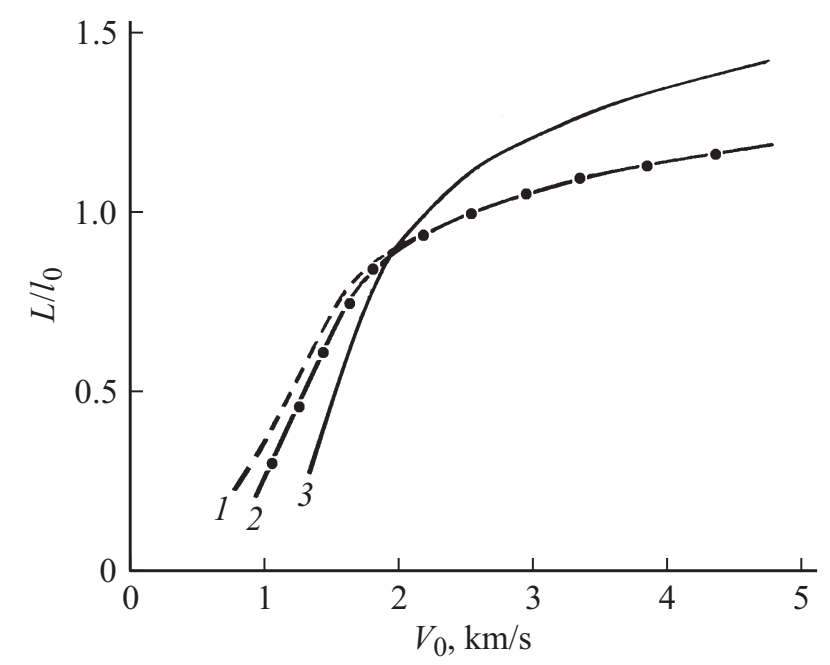

Pис. 3. Изменение относительной глубины проникания монолитных и пористых ударников с одинаковой плотностью материала. 


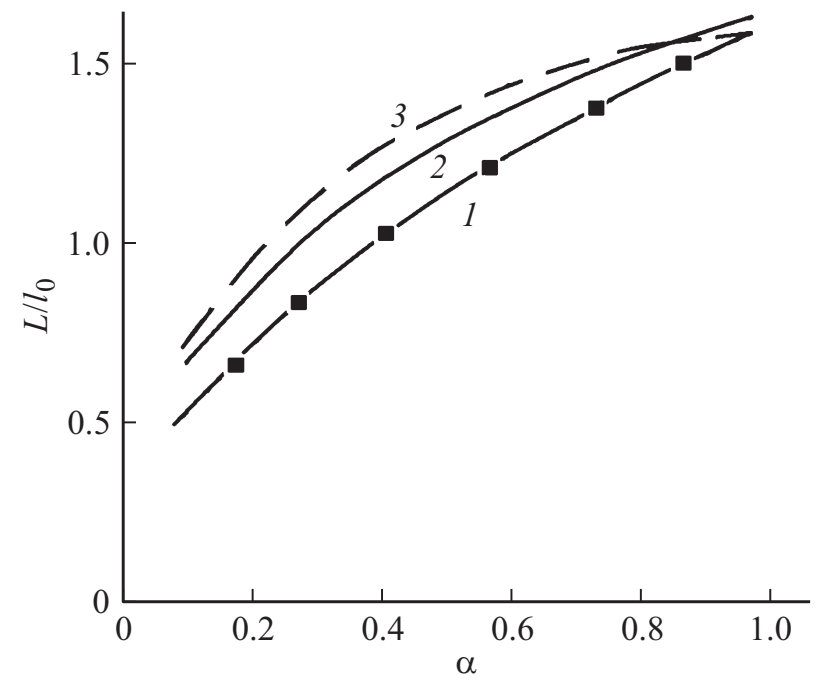

Рис. 4. Относительная глубина проникания ударников в зависимости от пористости материала.

проникать в преграду глубже. Эффект уменьшения диаметра кратера в случае проникания пористых ударников в сравнении с ударниками из монолитного материала отмечается и в $[4,5]$.

По результатам оценок (система уравнений (1)) и литературных данных $[5,16]$ проведен сравнительный анализ проникающей способности ударников из вольфрама различной пористости. В соответствии с гидродинамической теорией проникания (модель несжимаемой жидкости) [16] без учета прочностных характеристик взаимодействующих материалов глубина проникания определяется зависимостью:

$$
L / l_{0}=\sqrt{\rho_{00} / \rho_{t}}=\sqrt{\alpha} \sqrt{\rho_{0} / \rho_{t}} .
$$

В работе [5] предложено простое аналитическое соотношение для оценки глубины проникания пористого ударника в виде

$$
L / l_{0}=\sqrt{(2-\alpha)} \sqrt{\alpha} \sqrt{\rho_{0} / \rho_{t}} .
$$

Проведен сравнительный анализ результатов расчетов по рассмотренным методикам. На рис. 4 представлены графические зависимости относительной глубины проникания ударников в зависимости от пористости материала при скорости взаимодействия 4000 m/s. Кривая 1 получена по гидродинамической модели (соотношение (2)), кривая 2 характеризует прогноз глубины проникания по имитационной модели (система уравнений (1)), кривая 3 отражает зависимость, полученную по аналитическому соотношению (3).

В общем случае наблюдается тенденция увеличения проникающей способности ударников с уменьшением пористости материала ( $\alpha$ стремится к единице). Соотношения (2) и (3), полученные по представлениям гидродинамической теории проникания, в первом приближении будут справедливы для сверхвысоких скоростей соударения (кривые 1 и 3). Имитационная модель (1) в отличие от гидродинамической теории проникания учитывает прочностные характеристики материалов. Можно отметить удовлетворительное согласование результатов, полученных по соотношениям (1) и (3) - кривые 2 и 3 соответственно. Тем не менее наблюдается различие полученных результатов: кривая 3 стремится к гидродинамическому пределу проникания, а кривая 2, рассчитанная по модели (1), его превышает. Этот факт подтвержден экспериментальными исследованиями по внедрению стержневых ударников в преграды при сверхвысоких скоростях удара [21].

Таким образом, разработанная методика на основе модифицированной гидродинамической модели с учетом ударной сжимаемости материала ударника позволяет оценить интегральные параметры проникания стержневых ударников из пористых материалов. Результаты расчетов свидетельствуют об усилении проникающей способности высокопористых ударников в сравнении с монолитными при равенстве их массы и диаметра и при достаточно высоких скоростях удара. Этот эффект объясняется ускоренным образованием локализованных полос сдвига с последующим отделением фрагментов материала пористого ударника в сравнении с процессом проникания монолитных ударников.

\section{Финансирование работы}

В работе использованы результаты расчетов, полученные в ходе выполнения проекта № 8.2.09.2018 „Программа повышения конкурентоспособности Томского государственного университета“" и в рамках выполнения госзадания Томского научного центра Сибирского отделения Российской академии наук, проект № 0365-20180003. Экспериментальные результаты получены при финансовой поддержке Российского научного фонда в рамках проекта № 16-19-10264.

\section{Конфликт интересов}

Авторы заявляют, что у них нет конфликта интересов.

\section{Список литературы}

[1] Григорян В.А., Белобородько А.Н., Дорохов Н.С., Кобылкин И.Ф., Коновалов А.В., Маринин В.М., Соколов И.В. Частные вопросы конечной баллистики / Под ред. В.А. Григоряна. М.: Изд-во МГТУ им. Н.Э. Баумана, 2006. $592 \mathrm{c}$.

[2] Черняк Г.Б., Поварова К.Б. Вольфрам в боеприпасах / Под ред. И.Н. Торгуна. М.: ГНЦ РФ ФГУП „ЦНИИХМ““, 2014. 355 c.

[3] Герасимов А.В., Глазырин В.П., Зелепугин С.А., Коняев А.А., Орлов Ю.Н., Пашков С.В., Толкачев В.Ф., Трушков В.Г., Христенко Ю.Ф. Высокоскоростной удар. Моделирование и эксперимент / Под ред. А.В. Герасимова. Томск: Изд-во НТЛ, 2016. 568 с. 
[4] Абанасьева С.А., Белов Н.Н., Козорезов К.И., Табаченко А.Н., Хабибуллин М.В., Югов Н.Т. // ДАН. 1997. T. 355. № 2. C. 192-195. [Afanas'eva S.A., Belov N.N., Khabibullin M.V., Yugov N.T., Kozorezov K.I. // Phys. Dok. 1997. Vol. 42. N 7. P. 381-384.]

[5] Федоров С.В. // ЖТФ. 2007. Т. 77. Вып. 10. С. 131-134. [Fedorov S.V. // Tech. Phys. 2007. Vol. 52. N 10. P. 13791382. DOI: 10.1134/S1063784207100234]

[6] Ben-Dor G., Dubinsky A., Elperin T. // Mechanics Based Design of Structures and Machines. 2007. Vol. 35. N 4. P. 481-496. DOI: 10.1080/15397730701686959

[7] Федоров С.В., Бабкин А.В., Велданов В.А., Гладков Н.А., Ладов С.В. // Вестник МГТУ им. Н.Э. Баумана. Сер. Естественные науки. 2016. № 5 (68). С. 18-32. DOI: $10.18698 / 1812-3368-2016-5-18-32$

[8] Ищенко А.Н., Афанасьева С.А., Белов Н.Н., Буркин В.В., Рогаев К.С., Саммель А.Ю., Скосырский А.Б., Табаченко А.Н., Югов Н.Т. / Письма в ЖТФ. 2017. Т. 43. Вып. 17. C. 41-47. DOI: 10.21883/PJTF.2017.17.44945.16755 Ishchenko A.N., Afanas'eva S.A., Belov N.N., Burkin V.V., Rogaev K.S., Sammel'A.Yu., Skosyrskii A.B., Tabachenko A.N., Yugov N.T. // Tech. Phys. Lett. 2017. Vol. 43. N 9. P. 796-799. DOI: 10.1134/S1063785017090024]

[9] Зельдович Я.Б. // ЖЭТФ. 1957. Т. 32. № 6. С. 1577-1578.

[10] Зельдович Я.Б., Райзер Ю.П. Физика ударных волн и высокотемпературных гидродинамических явлений. М.: Физматлит, 2008. 656 с. [Zel'dovich Ya.B., Raizer Yu.P. Physics of shock waves and high-temperature hydrodynamic phenomena. NY: Mineola, 2002. 944 p.]

[11] Ударные волны и экстремальные состояния вещества / Под ред. В.Е. Фортова, Л.В. Альтшулера, Р.Ф. Трунина, А.И. Фунтикова. М.: Наука, 2000. 425 с.

[12] Румянцев Б.В., Михайлин А.И. // Письма в ЖТФ. 2018. Т. 44. Вып. 3. С. 62-68. DOI: 10.21883/PJTF.2018.03.45580.16970 [Rumyantsev B.V., Mikhailin A.I. // Tech. Phys. Lett. 2018. Vol. 44. N 2. P. 115-117. DOI: 10.1134/S1063785018020128]

[13] Савельева Н.В., Баяндин Ю.В., Савиных А.С., Гаркушин Г.В., Разоренов С.В., Наймарк О.Б. // Письма в ЖТФ. 2018. Т. 44. Вып. 18. С. 39-46. DOI: 10.21883/PJTF.2018.18.46610.17411 [Saveleva N.V., Bayandin Yu.V., Savinykh A.S., Garkushin G.V., Razorenov S.V., Naimark O.B. // Tech. Phys. Lett. 2018. Vol. 44. N 9. P. 823-826. DOI: 10.1134/S1063785018090286]

[14] Власов А.С., Синани А.Б. // ЖТФ. 2017. Т. 87. Вып. 7. C. 1033-1039. DOI: 10.21883/JTF.2017.07.44674.1992 [Vlasov A.S., Sinani A.B. // Tech. Phys. 2017. Vol. 62. N 7. P. 1049-1055. DOI: $10.1134 / \mathrm{S} 106378421707026 \mathrm{X}]$

[15] Румянцев Б.В. // Письма в ЖТФ. 2016. Т. 42. Вып. 17. C. 87-94. [Rumyantsev B.V. // Tech. Phys. Lett. 2016. Vol. 42. N 9. P. 923-926. DOI: 10.1134/S1063785016090078]

[16] Лаврентьев М.A. // Успехи математических наук. 1957. Т. 12. Вып. 4. С. 41-56.

[17] Алексеевский В.П. // Физика горения и взрыва. 1966. T. 2. № 2. C. 99-106. [Alekseevskii V.P. // Combustion, Explosion, and Shock Waves. 1966. Vol. 2. N 2. P. 63-66. DOI: $10.1007 / \mathrm{bf00749237}$

[18] Сагомонян А.Я. Проникание. М.: Из-во МГУ, 1974. 300 с.

[19] Экспериментальные данные по ударно-волновому сжатию и адиабатическому расширению конденсированных веществ / Под ред. Трунина Р.Ф. Саров: РФЯЦ-ВНИИЭФ, 2006. $531 \mathrm{c}$.

[20] Высокоскоростные ударные явления / Под ред. В.Н. Николаевского. М.: Мир, 1973. 533 с.

[21] Perez E. // Science et Techniques de l'Armement. 1982. Vol. 56. P. 1-155. 